\title{
AXIAL COMPRESSION TESTING OF BAMBOO PLYWOOD-ENCASED THIN-WALLED STEEL TUBE/STONE DUST CONCRETE COLUMNS
}

\author{
Weifeng Zhao \\ Guangdong Construction Polytechnic \\ China \\ Weifeng Zhao, Zongjian Luo, Yajun Li \\ Xiangtan University \\ College Of Civil Engineering And Mechanics \\ ChINA \\ Jing ZHOU \\ South China University Of Technology \\ China
}

(Received November 2020)

\begin{abstract}
A novel structural member, the bamboo plywood-encased thin-walled steel tube/stone dust concrete composite column (BSDCC), was investigated in this study. Axial compression tests were conducted on 10 BSDCC specimens; their failure characteristics and modes were examined, and the effects of the stone-dust concrete content ratio and strength, specimen slenderness ratio, cross-sectional composition and binding bar confinement pattern, and binding bar spacing ratio on the bearing capacity and deformation of the columns were investigated. Two main compressive failure modes were observed: (1) adhesive failure by cracking and debonding between the bamboo plywood boards and between the bamboo plywood and the steel tube and (2) compressiveflexural failure of the bamboo plywood between the binding bars in the middle of the specimen. For specimens with the same cross-sectional dimensions, the cross-sectional content ratio of the stone dust concrete impacted the deformation and failure mode but did not significantly affect the ultimate bearing capacity. The bearing capacity decreased with increasing specimen slenderness and binding bar spacing ratio and increased with increasing stone dust concrete strength and bamboo plywood constraint (in terms of the cross-sectional composition and binding bar restraint pattern). A model for the ultimate bearing capacity of BSDCCs was established through regression analysis.
\end{abstract}

KEYWORDS: Bamboo plywood, thin-walled steel tube, stone dust concrete, composite column, axial compression testing. 


\section{INTRODUCTION}

The dwindling engineering wood supply and growing acceptance of sustainably developed green building materials have resulted in the widespread use of bamboo as a renewable biomass material in the civil engineering field (Sharma et al. 2015, Zhang et al. 2015, He et al. 2015). In particular, the successful development of laminated bamboo has broadened the application of bamboo in engineering (Reynolds et al. 2016, Kumar et al. 2016). Tian et al. (2019) studied the compressive behaviour of sprayed composite mortar-original bamboo columns and found that their ultimate load and ductility are 1.5 and 2.6 times higher than those of the original bamboo column, respectively. Li et al. (2017) reported that the axial load bearing capacities and the initial stiffness of both concrete-filled and cement-mortar-filled bamboo columns are much higher than those of conventional bamboo columns. Moroz et al. (2014), Siddika et al. (2017), and Nayak et al. (2013) considered the use of bamboo-reinforced concrete members as an alternative to the use of steel members. Li et al. $(2015,2016,2019)$ investigated the mechanical performance of laminated bamboo columns under axial and eccentric compression over a wide range of slenderness ratios and eccentricities. Wei et al. (2016) investigated the eccentric compression performance of a novel bamboo column and proposed a calculation method. Zhao et al. (2019, 2020) proposed a novel structural member: a thin-walled steel tube/bamboo plywood composite column with binding bars (SBCCB). The compression damage of a SBCCB was found to primarily occur by breaking of the bamboo plywood and adhesive failure between the matrix interfaces at the end and middle of the column between the binding bars.

There are very few studies on the application of stone dust. Aliabdo et al. (2014) studied the performance of concrete in which marble stone dust was used to replace cement or river sand. Kandolkar et al. (2015) used recycled stone dust as an admixture in the construction of bamboo or steel-reinforced concrete walls. Arel et al. (2016) conducted experiments to determine how replacing cement with stone dust affected the mechanical properties of a concrete. Singh et al. (2016) replaced a portion of river sand with stone dust and investigated the durability of the resulting concrete. Febin et al. (2019) found that the compressive and splitting strengths of cement blocks were significantly improved by the incorporation of stone dust. However, studies on the application of stone dust are still scarce (Zheng et al. 2017). Because the use of stone dust in large amounts as concrete admixtures decreases the strength of the concrete, research on the applications of stone dust could have enormous social and economic benefits.

In the present study, a novel bamboo plywood-encased thin-walled steel tube/stone dust concrete composite column (BSDCC) was proposed to integrate the utilization of stone dust waste and bamboo plywood. The composite column in this study is clearly different from the bamboo plywood and thin-walled steel tube hollow-core column (the SBCCB) proposed by Zhao et al. $(2019,2020)$. In a BSDCC, the square thin-walled steel tube is filled with low-strength stone dust concrete, which not only disposes of a large amount of industrial solid waste but also promotes the recycling and reuse of waste resources; the resulting composite column has a steel tube/concrete configuration, which has better and more stable mechanical properties than those corresponding to the SBCCB configuration because the new form changes the force failure mechanism. The new type of composite column adopts a cross-sectional configuration of bamboo plywood and a thin-walled steel tube to constrain the stone dust concrete. The thin-walled steel tube plays the role of not only a lining but also a water barrier between the stone dust concrete and the bamboo plywood; at the same time, including binding bars can result in a good hoop effect, increase the horizontal restraint force, and improve the integrity of the composite column. Axial compression tests were carried out on $10 \mathrm{BSDCC}$ specimens to examine the failure characteristics 
and modes of the specimens and investigate the effects of the bearing capacity and deformation of the specimen on the failure characteristics and modes.

\section{MATERIAL AND METHODS}

\section{Specimen preparation}

Ten BSDCC specimens were subjected to axial compression tests. The parameters of the specimens are listed in Tab. 1, the cross-sectional compositions and binding bar confinement patterns are shown in Fig. 1, and the configuration is shown schematically in Fig. 2a. Specimens $\mathrm{AC}-1, \mathrm{AC}-2$, and $\mathrm{AC}-3$ were compared to examine the effects of the cross-sectional content ratios of stone dust concrete and bamboo plywood. Specimens AC-2, AC-4, and AC-5 were compared to investigate the influence of the slenderness ratio $\lambda$. Specimens AC-4, AC-6, and AC-7 were compared to study the effect of the cross-sectional composition and binding bar confinement pattern. Specimens AC-5, AC-8, and AC-9 were compared to study the effect of the binding bar spacing ratio $\left(r_{1}\right)$. Specimens AC-6 and AC-10 were compared to examine the influence of the stone dust concrete strength. The $\lambda$, stone dust concrete content ratio $(\rho)$, and $r_{1}$ of a specimen were calculated using the following formulas:

$$
\begin{aligned}
& \lambda=L / B \\
& \rho=A_{\mathrm{c}} / A \\
& r_{1}=s / B
\end{aligned}
$$

where: $L$ is the length of the specimen, $B$ is the side length of the cross-section, $\mathrm{A}$ is the crosssectional area of the specimen, $A_{\mathrm{c}}$ is the cross-sectional area of the stone dust concrete, and

\begin{tabular}{|c|c|c|c|c|c|c|c|c|c|c|}
\hline $\begin{array}{l}\text { Specimen } \\
\text { number }\end{array}$ & $\lambda$ & $\begin{array}{l}\text { Concrete } \\
\text { strength } \\
(\mathrm{MPa})\end{array}$ & $\begin{array}{c}\text { Confinement } \\
\text { patterns }\end{array}$ & $\begin{array}{c}\text { Section } \\
\text { of steel tube } \\
(\mathrm{mm})\end{array}$ & $\begin{array}{c}\text { Bamboo } \\
\text { plywood } \\
\text { layers }\end{array}$ & $r_{1}$ & $\begin{array}{c}\text { Bamboo } \\
\text { plywood } \\
\text { content } \\
\text { ratio/\% }\end{array}$ & $\begin{array}{l}\text { Steel } \\
\text { tube } \\
\text { content } \\
\text { ratio } \\
(\%)\end{array}$ & $\underset{(\%)}{\rho}$ & $L / \mathrm{mm}$ \\
\hline $\mathrm{AC}-1$ & 8 & 9.0 & $\square$ & $60 \times 60 \times 2$ & 4 & 2 & 81.6 & 1.2 & 17.2 & 1120 \\
\hline $\mathrm{AC}-3$ & 8 & 9.0 & $\square$ & $100 \times 100 \times 2$ & 2 & 2 & 49.0 & 2.0 & 49.0 & 1120 \\
\hline $\mathrm{AC}-4$ & 12 & 9.0 & $\square$ & $80 \times 80 \times 2$ & 3 & 2 & 67.3 & 1.6 & 31.1 & 1680 \\
\hline $\mathrm{AC}-5$ & 16 & 9.0 & $\square$ & $80 \times 80 \times 2$ & 3 & 2 & 67.3 & 1.6 & 31.1 & 2240 \\
\hline $\mathrm{AC}-8$ & 16 & 9.0 & $\square$ & $80 \times 80 \times 2$ & 3 & 1 & 67.3 & 1.6 & 31.1 & 2240 \\
\hline $\mathrm{AC}-9$ & 16 & 9.0 & $\square$ & $80 \times 80 \times 2$ & 3 & 3 & 67.3 & 1.6 & 31.1 & 2240 \\
\hline $\mathrm{AC}-10$ & 12 & 14.2 & $\square$ & $80 \times 80 \times 2$ & 3 & 2 & 67.3 & 1.6 & 31.1 & 1680 \\
\hline
\end{tabular}
$s$ is the spacing between the binding bars.

Tab. 1: Parameters of the specimens. 


\section{Material properties}

Moso bamboo plywood, from the same batch, with dimensions of $2440 \times 1220 \times 10 \mathrm{~mm}^{3}$ (length $\times$ width $\times$ thickness) was used in this work. The moisture content was $9 \%$, the transverse and longitudinal static bending strengths were $52 \mathrm{MPa}$ and $83 \mathrm{MPa}$, respectively, the transverse and longitudinal moduli of elasticity were $7.4 \mathrm{GPa}$ and $8.3 \mathrm{GPa}$, respectively, and the longitudinal compressive strength was $24 \mathrm{MPa}$. Seamless thin-walled square steel tubes with a thickness of $2 \mathrm{~mm}$ and fully threaded $\varnothing 8$ binding bars were used to create the specimens. The properties of the binding bars and thin-walled steel tubes were tested according to the GB/T228.1 standard (2011). The yield strength and elastic modulus of each steel tube were $350 \mathrm{MPa}$ and $190 \mathrm{GPa}$, respectively. The yield strength and elastic modulus of each binding bar were $260 \mathrm{MPa}$ and $193 \mathrm{GPa}$, respectively. EP120 epoxy resin AB glue (Ausbond, China) was used as an adhesive, which has a shrinkage ratio $<1 \%$, tensile strength $>10 \mathrm{MPa}$, and shear strength $<12 \mathrm{MPa}$. The dust powder was provided by the Foshan Ceramics Plant and was air-dried and used as an admixture. The dust powder was incorporated as a cementitious material into concrete at a certain ratio to produce low-strength dust-powder-containing concrete. Uniaxial compressive strength tests were performed on the cubic specimens as per the GB/T50081 standard (2019). The stone dust concrete was designed to have compressive strength values of $9.0 \mathrm{MPa}$ and 14.2 $\mathrm{MPa}$ and elastic moduli of $16.4 \mathrm{GPa}$ and $21.7 \mathrm{GPa}$.

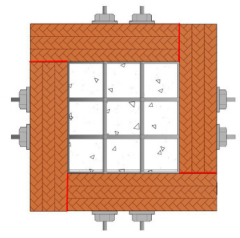

(a)

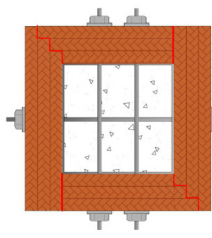

(b)

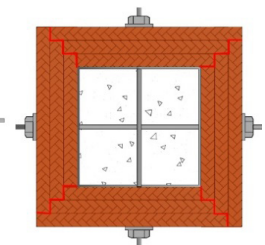

(c)

Fig. 1: Cross-sectional composition and binding bar confinement patterns: (a) pattern I; (b) pattern II; (c) pattern III.
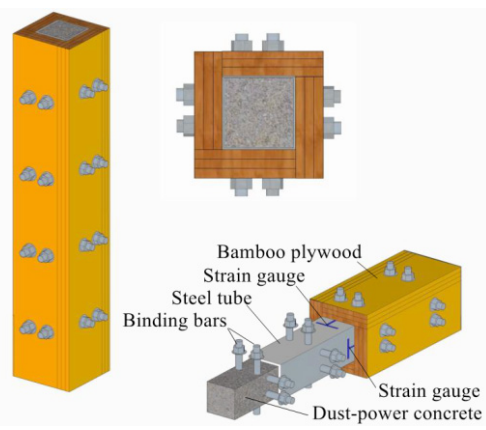

(a)

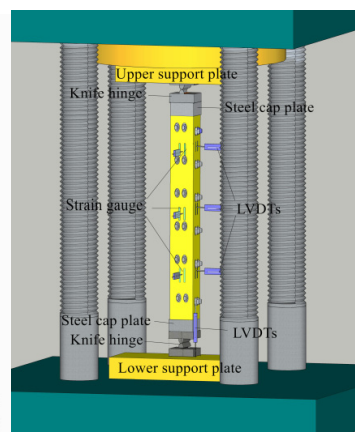

(b)

Fig. 2: Schematic: (a) BSDCC components; (b) test device.

\section{Test method}

The test apparatus and measuring point arrangement are shown in Fig. 2b. Vertical loads were transferred to both ends of the specimen through unidirectional knife hinges. A steel cap plate with a depth of $40 \mathrm{~mm}$ was placed between the column end and the knife hinge plate to constrain the bamboo plywood at the column end, and a thin layer 
ofhigh-strength plasterwasappliedinsidethesteelcapplateforlevelling. Thelongitudinaldeformation of the specimen was measured by displacement gauges installed on the pressing plates of the testing machine. A total of six horizontal displacement gauges were placed on the upper, middle, and bottom surfaces of two adjacent sides of the specimen to measure the lateral deformation. The transverse and vertical strains of the thin-walled steel tube and bamboo plywood were measured by strain gauges arranged on the two adjacent sides of the thin-walled steel tube and bamboo plywood. The test loads, displacements, and strains were collected automatically by a static data acquisition system. The load was applied uniformly at a slow rate under displacement control. The test was terminated when the specimen underwent considerable cracking or its deformation increased rapidly, and the corresponding peak load was taken as the ultimate bearing capacity of the specimen.

\section{RESULTS AND DISCUSSION}

\section{Phenomena and failure characteristics}

The failure processes of all the specimens exhibited similar mechanical behaviour, while their failure modes had different characteristics due to the different parameters considered. At the initial stage of loading, the specimen was basically in an elastic stage. When the loading reached $50 \%$ to $60 \%$ of the ultimate load, intermittent short, faint cracking sounds were detected, and fine cracks occurred in the bamboo plywood between the binding bars, indicating adhesive cracking due to the shear stress and the normal tensile stress between the bamboo plywood boards exceeding the bond strength. As the load reached approximately $70 \%$ of the ultimate load, a loud cracking sound occurred, the original cracks gradually developed further, the bamboo plywood locally bulged outwardly, and the axial compressive deformation increased. At this time, the binding bars were tightened, and the bamboo plywood near the binding bars remained intact. As the peak load was approached, the cracks developed rapidly and approached the binding bars. A relatively loud cracking sound occurred, and the bamboo plywood between the binding bars in the middle of some specimens completely deboned, bulged, and failed under compression and flexure. In the failure zone, the bamboo plywood basically stopped resisting the load, and the stone dust concrete-filled steel tube bore the load alone. Due to its small cross-sectional dimensions, the concrete-filled steel tube had a limited lateral stiffness; hence, the lateral deflection in the middle of the column increased rapidly, causing the loss of the vertical bearing capacity and the overall failure of the specimen. The binding bars of each specimen were in a stable stress state and did not exhibit significant shear deformation or failure. The binding bars and the stone dust concrete-filled steel tube produced a confinement effect, which inhibited the development of adhesive cracking in the bamboo plywood, strengthened the deformation compatibility of various matrices, and improved the integrity of the composite column. The failure modes of the specimens are presented in Fig. 3, and Fig. 4 shows the failure process using specimen AC-3 as an example.

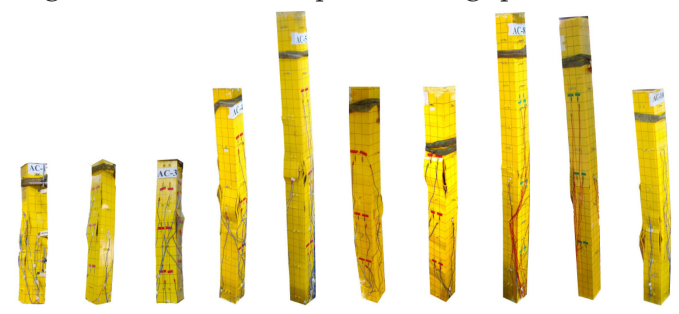

$A C-1 \quad A C-2$ AC-3 AC-4 AC-5 AC-6 AC-7 AC-8 AC-9 AC-10

Fig. 3: Failure modes of all the specimens. 


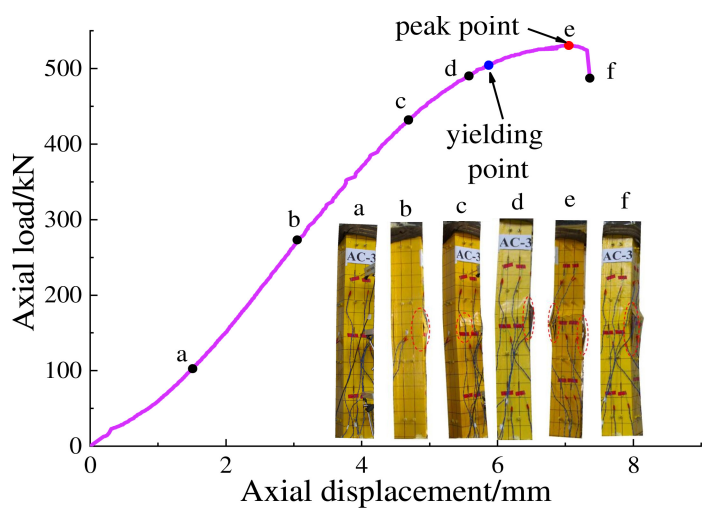

Fig. 4: Damage process of specimen $A C-3$.

As revealed by the test phenomena, the failure modes of the specimens differed to various degrees and can be divided into three main types, namely, the adhesive cracking and debonding of the bamboo plywood and thin-walled steel tube between the binding bars in the middle of the specimen, adhesive cracking between bamboo plywood boards, and bamboo plywood material failure under compression and flexure. In the compressive-flexural failure zone of the bamboo plywood, the thin-walled steel tube buckled at the corresponding location (Fig. 5c). The typical compressive failure modes are as follows: (1) Compressive-flexural failure of bamboo plywood on one side. For specimens AC-5, AC-8, and AC-9, which had relatively high slenderness ratios, the bearing surface was not perpendicular to the axis of the specimen due to inevitable material nonuniformities. Hence, the second-order effect of flexure occurred on the weak side of the specimen during the axial compression process and generated an additional bending moment, which led to nonuniform compression of the cross-section, causing compressive-flexural failure of the bamboo plywood on the side with a high compressive stress. (2) Compressiveflexural failure of bamboo plywood in a barrel shape. For specimens AC-1, AC-2, and AC-3, which had relatively low slenderness ratios, the second-order effect of flexure was relatively weak. During the loading process, each specimen was basically in an axial compression state, and the cross-section was relatively uniformly stressed. When the axial compression load was close to the ultimate bearing capacity, the bamboo plywood on each of the four sides of the core column basically reached the ultimate strength, thereby resulting in compressive-flexural failure of the bamboo plywood in a barrel shape, and the material strength was fully utilized

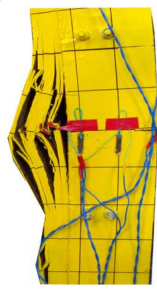

(a)

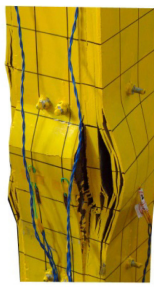

(b)

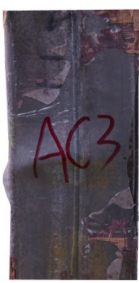

(c)

Fig. 5: Specimen failure modes: (a) bamboo plywood failure on one side of the specimen, (b) barrel-shaped bamboo plywood failure, and (c) buckling of the steel tube. 


\section{Load-displacement/strain responses}

Effect of cross-sectional material content ratio

Fig. 6 compares the load-displacement/axial compressive strain curves of specimens AC-1, AC-2, and AC-3, which have different stone dust concrete and bamboo plywood content ratios. The three specimens had the same cross-sectional dimensions but had different net cross-sectional areas of stone dust concrete, bamboo plywood and thin-walled steel tubes, as shown in Tab. 1.

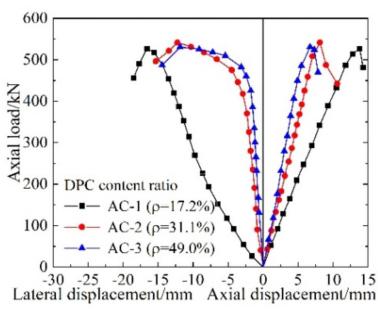

(a)

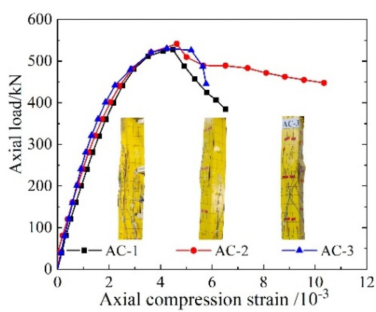

(b)

Fig. 6: Effect of the material content ratio: (a) load-displacement curves and (b) bamboo plywood loadstrain curves.

The three specimens differed little in ultimate bearing capacity (with a ratio of 1:1.03:1.01) but differed substantially in axial and lateral deformation. Specimen AC-1 had a low net cross-sectional ratio of stone dust concrete (17.2\%) and a high net cross-sectional ratio of bamboo plywood (81.6\%). Since the compressive strength and flexural stiffness of the stone dust concrete were higher than those of the bamboo plywood, specimen AC- 1 had low overall axial and lateral stiffnesses and hence high axial and lateral deformation. The axial and lateral deformation values of specimen AC-2 were only slightly greater than those of specimen AC-3, indicating that overall, the two specimens had comparable axial and lateral stiffnesses. Specimen AC-3 had a greater net cross-sectional ratio of stone dust concrete (49.0\%); thus, more dust powder waste could be utilized, but the load bearing capacity tended to decrease. Before the peak load was reached, the vertical strains of the three specimens were basically the same, whereas after the peak load, the vertical strain of the bamboo plywood in specimen AC-2 was the most fully developed, indicating that the bamboo strength was fully utilized. Overall, the cross-sectional material content ratio of a specimen had an important influence on its compression performance. The proportions of different components can be adjusted to obtain the optimized stiffness and bearing capacity to maximize the use of material strength.

\section{Effect of the stone dust concrete strength}

The load-displacement/axial compressive strain curves of specimens AC-6 and AC-10, which had different stone dust concrete strengths, are compared in Fig. 7. The compressive strength values of the stone dust concrete were $9.0 \mathrm{MPa}$ and $14.2 \mathrm{MPa}$, respectively. The axial and lateral deformations of the two specimens were not significantly different, but the bearing capacity of specimen AC-6 was significantly lower than that of AC-10 (with a bearing capacity ratio of 1:1.14), indicating that the specimen with a high stone dust concrete strength had a relatively high bearing capacity. The stone dust concrete of specimen AC-10 had a greater elastic modulus; in the elastic deformation stage and under the same axial compression as that of specimen AC-6, the strain in specimen AC-10 developed more slowly, and the adhesive cracking and debonding failure of the bamboo plywood was delayed, thus resulting in a higher ultimate 
bearing capacity. The vertical strain of the bamboo plywood in specimen AC- 6 developed more thoroughly, indicating that the strength of the bamboo plywood material in AC-6 was better utilized and that the bamboo plywood resisted a greater portion of the vertical load. In the present study, only two specimens were designed to examine the influence of the stone dust concrete strength. More tests and numerical simulation analyses are needed further investigate the trend of the influence of stone dust concrete strength on the deformation compatibility and bearing capacity of such composite columns.

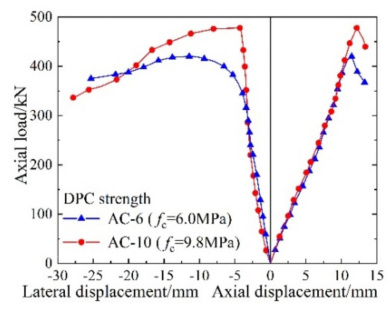

a)

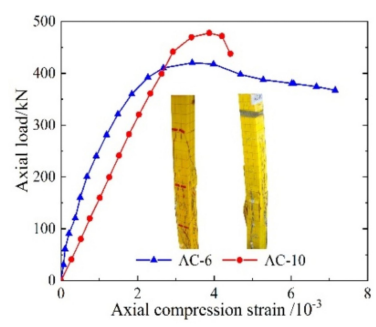

(b)

Fig. 7: Effect of the stone dust concrete strength: (a) Axial load-displacement curves; (b) bamboo plywood load-strain curves.

\section{Effect of slenderness ratio}

Fig. 8 shows the load-displacement/axial compressive strain curves of specimens AC-2, AC-4, and AC-5, which had different slenderness ratios $(\lambda) . \lambda$ had a significant impact on the ultimate compressive bearing capacity and deformation of the specimen, and the basic pattern was that a low $\lambda$ corresponded to a high ultimate bearing capacity and low vertical and lateral deformations. The three specimens had the same cross-sectional dimensions and material composition ratios and hence the same axial compressive stiffness, but the specimen with a low $\lambda$ underwent a relatively small compressive deformation $(\Delta L=N L / E A$, which is only related to the length of the specimen, where $N$ is the axial load and $E A$ is the stiffness of the specimen under axial compression). In addition, the specimen with a low $\lambda$ had a high ultimate axial compressive strain of bamboo plywood, indicating that the material strength was more fully utilized. For example, specimen AC-2 $(\lambda=8)$ had a small axial compressive deformation, and its ultimate compressive strain was significantly greater than that of specimen AC-5 $(\lambda=16)$. According to the Euler principle, AC-5, with a high $\lambda$, had a lower ultimate bearing capacity, a relatively short linear elastic stage, and a reduced stability under axial compression than those of specimens AC-2 and $\mathrm{AC}-4$, and specimen $\mathrm{AC}-5$ was more sensitive to the second-order effect of flexure, leading to an increase in lateral deformation. The bearing capacities of specimens $\mathrm{AC}-2, \mathrm{AC}-4$, and $\mathrm{AC}-5$ were at a ratio of 1:0.81:0.73, indicating that the bearing capacity decreased as $\lambda$ increased. Specimen AC-4 $(\lambda=12)$ underwent the largest lateral deformation, probably because the local initial imperfection of bamboo plywood caused the earlier occurrence of the second-order effect of flexure. The vertical strain curve of the bamboo plywood in specimen AC-4 shows relatively fast development, with a difference from that of the other two specimens even in the initial stage and a long elastoplastic stage before the peak load. 


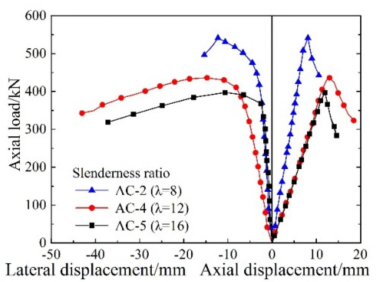

a)

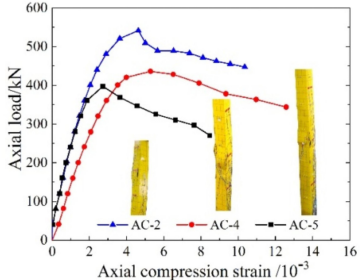

(b)

Fig. 8: Effect of the slenderness ratio: (a) Axial load-displacement curves; (b) bamboo plywood load-strain curves.

\section{Effect of the cross-sectional composition and binding bar confinement pattern}

Fig. 9 compares the load-displacement/axial compressive strain curves of specimens AC-4, AC-6, and AC-7, which had different cross-sectional composition and binding bar confinement patterns. As Fig. 9(a) shows, specimen AC-7 (pattern III) had the highest bearing capacity, specimen AC-4 (pattern I) and specimen AC-6 (pattern II) had similar bearing capacities, and the ultimate bearing capacities of AC-4, AC-6, and AC-7 had a ratio of 1:0.96:1.11, indicating that the bamboo plywood composition with a layer-staggered interlocking pattern and an increase in the number of transverse binding bars could improve the overall compressive bearing capacity. The composition effect was closely related to the interlocking of the inner and outer bamboo plywood boards at the bonding interface and the confinement by the binding bars. As shown in Fig. 1, if a single piece of bamboo plywood on the cross-section of the specimen had a width of $b$, the bonding interface at the end of specimen AC-7 (pattern III) had a length of $20 \mathrm{~b}$. The layer-staggered interlocking outer bamboo plywood suppressed the adhesive cracking failure of the inner bamboo plywood. The bonding interface at the end of specimen AC-4 (pattern I) had a length of $12 b$. Although there was no staggered interlocking confinement at the end of $\mathrm{AC}-4$, this specimen had one additional binding bar compared to those of specimen AC-7 (pattern III) in each of the two directions of its cross-section. The binding bars and the concrete-filled steel tube in the core zone played the role of transverse stirrups, which produced a confinement effect and thus achieved the same composition effect. Specimen AC-6 (pattern II) was a combination of the construction of specimen AC-4 and specimen AC-7, clearly achieving an improved result. The development of the vertical strain in the bamboo plywood of specimen AC-7 was relatively short, indirectly indicating that the inner bamboo plywood, thin-walled steel tube, and stone dust concrete play a considerable role in the performance of this specimen.

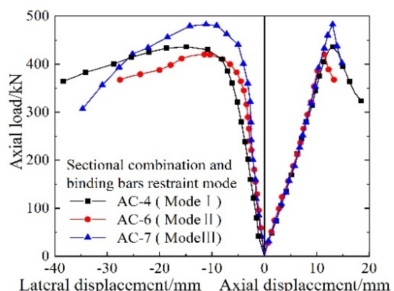

a)

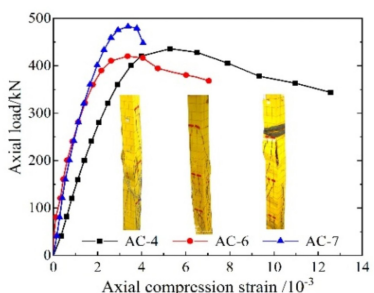

(b)

Fig. 9: Effect of the cross-sectional composition and binding bar restraint mode: (a) axial load-displacement curves; (b) bamboo plywood load-strain curves. 


\section{Effect of the binding bar spacing ratio}

Fig. 10 compares the load-displacement/axial compressive strain curves of specimens AC-5, AC-8, and AC-9, which had binding bar spacing ratios $\left(r_{1}\right)$ of 2,1 , and 3 , respectively. The ultimate bearing capacities of these specimens exhibited a ratio of 1:0.89:0.94, so specimen AC-5 had the highest ultimate bearing capacity. The parameter $r_{1}$ directly affected the local adhesive cracking failure. A reasonable binding bar spacing could effectively improve the local buckling strength of the thin-walled steel tube and bamboo plywood. Through the confinement of the lateral deformation of the thin-walled steel tube and bamboo plywood, the failure mode of the specimen changed, and the bearing capacity improved. It can be seen from the comparison of the failure modes of the three specimens that the local cracking of the specimen significantly increased with $r_{1}$. The binding bars with a low $r_{1}$ worked with the thin-walled steel tube to produce a confinement effect, which effectively inhibited the local adhesive cracking and debonding of the bamboo plywood and enhanced the integrity of the composite specimen. In addition, the deformation and strain compatibility of the bamboo plywood and thin-walled steel tube increased, changing the compressive failure mode and thereby improving the compression and deformation resistance of the specimen. As shown in Fig. 10c, specimen AC-8, which had a low $r_{1}$, exhibited synchronized vertical strains in the bamboo plywood and thin-walled steel tube, indicating that the two materials could work together. For specimen AC-9, in the early stage of loading, the difference between the strains of the bamboo plywood and thin-walled steel tube was relatively small; as the axial load increased further, the vertical strains of the two materials became very different, resulting in a continuous decrease in the axial stiffness of the specimen. In addition, compared to AC-5 and AC-8, AC-9 had significantly low ultimate strains in these two materials, indicating that their material strengths were not fully utilized.

In specimen $\mathrm{AC}-8$, local adhesive cracking failure occurred relatively late, and the axial compressive strain of the bamboo plywood was fully developed. However, its bearing capacity was not much different from that of specimen AC-9, which might be due to the deviation in the materials used for specimen preparation as well as in the installation process, a topic that needs to be further investigated in the future. Considering the product manufacturing process, a lower $r_{1}$ value does not lead to better structural performance. An $r_{1}$ value of 2 can be used to obtain a reasonable design.

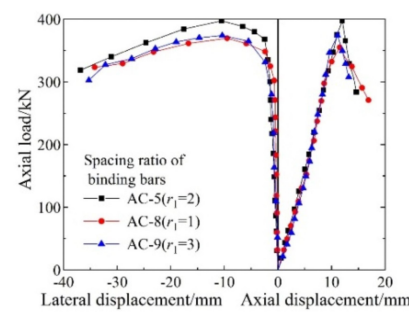

(a)

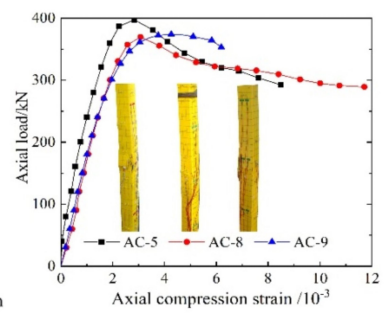

(b)

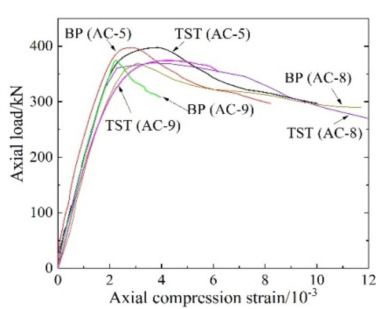

(c)

Fig. 10: Effect of the binding bar spacing ratio: (a) axial load-displacement curves, (b) bamboo plywood load-strain curves; (c) comparison of strain curves.

\section{Characteristic points and ductility}

Tab. 2 shows the characteristic points of the axial compressive load-deformation curves and the corresponding axial compression deformation ductility factors. In the ascending part of an axial compressive load-axial deformation curve, the equivalent energy method is 
used to determine the yield load $\left(N_{\mathrm{y}}\right)$ and the yield displacement $\left(\Delta_{\mathrm{y}}\right)$. In the descending part of the curve, the displacement corresponding to the time when the load drops to $85 \%$ of the peak load is taken as the ultimate displacement $\left(\Delta_{\mathrm{u}}\right)$. The axial deformation ductility factor is defined in Eq. 4:

$$
\mu=\Delta_{\mathrm{u}} / \Delta_{\mathrm{y}}
$$

Bamboo has a high elastic deformation capacity but does not exhibit favourable elastoplastic or plastic deformation behaviours. For the BSDCCs studied here, the proportion of bamboo plywood in the cross-section was relatively large, and the stone dust concrete had a lower elastic modulus than ordinary concrete. Therefore, overall, the BSDCC specimens exhibited mechanical behaviour similar to that of bamboo. Compared to other concrete composite columns (Liu et al. 2015), the specimens tested in the present study exhibited higher axial compression yield displacement ratios $\left(\Delta_{y} / L\right)$ but did not have higher axial compression plastic displacement ratios $\left(\left(\Delta_{\mathrm{u}}-\Delta_{\mathrm{y}}\right) / L\right)$. In particular, the bearing capacity of a specimen declined rapidly after the peak load, and the plastic deformation development stage was very short, indicating that the specimen did not demonstrate advantageous plastic deformation behaviour and underwent brittle failure. Hence, overall, the corresponding axial compression deformation ductility factor was relatively low. In future work, the cross-sectional configuration and the comprehensive performance of the design will need to be optimized in terms of ultimate bearing capacity and plastic deformation, and the cross-sectional content ratio of the stone dust concrete will need to be increased.

To further investigate the influence of the binding bar confinement pattern and the encased stone dust concrete on the axial bearing capacity of the specimen, the ultimate compressive stresses of the specimens tested in the present study are compared with those of thin-walled steel tube/bamboo plywood composite hollow short columns with a single row of binding bars (SBCCBs) (Zhao et al. 2020), as shown in Fig. 11. The average ultimate compressive stress of the SBCCBs is $20.29 \mathrm{MPa}$, while that of the BSDCCs is $23.23 \mathrm{MPa}$, amounting to a $14.53 \%$ increase. Thus, filling the steel tube with low-strength stone dust concrete significantly increased the average compressive stress of the specimens. Therefore, each BSDCC specimen had a relatively good coupling effect, which determined the failure mode of the specimen and caused the strength of the bamboo plywood to be fully utilized, highlighting the advantages of this new type of composite column.

Tab. 2: Characteristic points and specimen ductility.

\begin{tabular}{|c|c|c|c|c|c|c|c|}
\hline Specimen number & $\begin{array}{c}N_{\boldsymbol{y}} \\
(\mathbf{k N})\end{array}$ & $\begin{array}{c}\Delta_{\boldsymbol{y}} \\
(\mathrm{mm})\end{array}$ & $\begin{array}{c}\Delta_{\boldsymbol{y}} / \mathbf{L} \\
(\%)\end{array}$ & $\begin{array}{c}\boldsymbol{N}_{\boldsymbol{u}} \\
(\mathbf{k N})\end{array}$ & $\begin{array}{c}\Delta_{u} \\
(\mathbf{m m})\end{array}$ & $\begin{array}{c}\left(\Delta_{u}-\Delta_{\boldsymbol{y}}\right) / \mathbf{L} \\
(\%)\end{array}$ & $\boldsymbol{\mu}$ \\
\hline AC-1 & 499.12 & 12.62 & 1.13 & 527 & 14.30 & 0.15 & 1.13 \\
\hline AC-2 & 526.29 & 7.64 & 0.68 & 541.4 & 9.81 & 0.19 & 1.28 \\
\hline AC-3 & 503.12 & 5.97 & 0.53 & 530.6 & 7.56 & 0.14 & 1.27 \\
\hline AC-4 & 482.78 & 12.61 & 0.75 & 436.08 & 16.17 & 0.21 & 1.28 \\
\hline AC-5 & 396.47 & 11.96 & 0.53 & 397.4 & 13.30 & 0.06 & 1.11 \\
\hline AC-6 & 413.62 & 11.64 & 0.69 & 420.25 & 13.29 & 0.10 & 1.14 \\
\hline AC-7 & 460.48 & 13.44 & 0.80 & 482.82 & 14.61 & 0.07 & 1.10 \\
\hline AC-8 & 350.28 & 11.23 & 0.50 & 369.6 & 15.60 & 0.20 & 1.39 \\
\hline AC-9 & 350.28 & 11.23 & 0.50 & 374.1 & 12.80 & 0.07 & 1.14 \\
\hline AC-10 & 466.55 & 12.66 & 0.75 & 477.8 & 13.40 & 0.03 & 1.06 \\
\hline
\end{tabular}




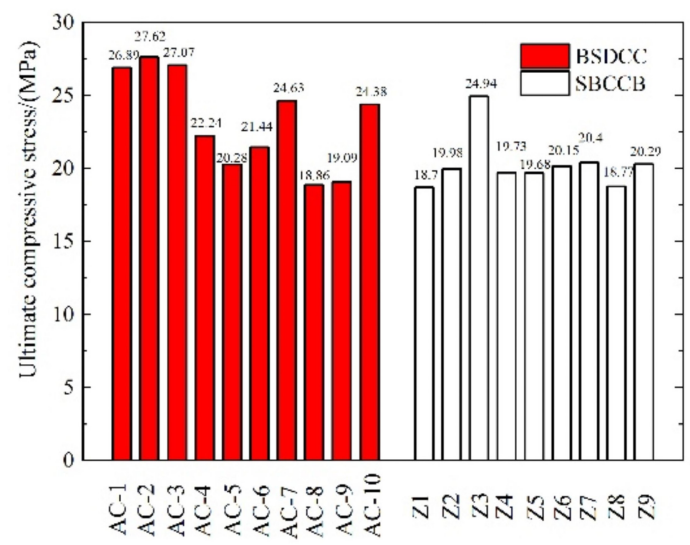

Fig. 11: Comparison of compressive stresses observed in this study with those observed in other studies (Zhao et al. 2020).

\section{Model for estimating bearing capacity under axial compression}

The ultimate bearing capacity of a BSDCC is affected by a multitude of factors but generally follows certain patterns. The axial bearing capacity of a BSDCC is not only related to factors such as the specimen slenderness ratio, stone dust concrete strength, and cross-sectional material content ratio but also affected by the cross-sectional composition and binding bar confinement pattern. According to the above analysis, the ultimate bearing capacities of specimens with patterns I and II were not very different, and those of pattern III were relatively high. Comprehensive consideration of the bearing capacity and manufacturing factors shows that the cross-sectional composition of pattern I is recommended; accordingly, the influence of the other patterns is not taken into account. With reference to the timber structure design standard (2017), a model for calculating the ultimate bearing capacity is established based on the superposition principle. The axial compression stability coefficient $(\varphi)$ is decomposed into the product of the slenderness ratio influence coefficient $\left(\varphi_{\lambda}\right)$ and the binding bar influence coefficient $\left(\varphi_{\mathrm{r}}\right)$. The bearing capacity model is constructed as follows:

$$
\begin{aligned}
& N_{\mathrm{u}}=\varphi_{\lambda} \varphi_{r}\left(f_{b} A_{b}+f_{s} A_{s}+f_{c} A_{c}\right) \\
& \varphi_{\lambda}=\frac{1}{1+\left(\lambda / \alpha_{1}\right)^{2}} \\
& \varphi_{r}=1+\frac{\alpha_{2} r_{2}}{r_{1}}
\end{aligned}
$$

where $f_{\mathrm{b}}$ is the longitudinal compressive strength of the bamboo plywood, $f_{\mathrm{s}}$ is the yield strength of the thin-walled steel tube, $f_{\mathrm{c}}$ is the compressive strength of the stone dust concrete, $A_{\mathrm{b}}$ is the net cross-sectional area of the bamboo plywood, $A_{\mathrm{s}}$ is the net cross-sectional area of the thin-walled steel tube, $A_{\mathrm{c}}$ is the net cross-sectional area of the stone dust concrete, $r_{1}$ and $r_{2}$ are the relative spacing ratio and number of rows of the binding bars, respectively, and $\alpha_{1}$ and $\alpha_{2}$ are fitting parameters.

A nonlinear regression analysis was performed to obtain the simplified parameters 
$\alpha_{1}=16.45$ and $\alpha_{2}=0.11$, with an overall correlation coefficient of $R^{2}=0.85$. Tab. 3 compares the test values and the calculation values of the ultimate bearing capacity, which have absolute errors of less than $15 \%$, showing that the calculation results agree well with the test results.

Tab. 3: Comparison of the test and calculated results.

\begin{tabular}{|c|c|c|c|}
\hline Specimen number & $\begin{array}{c}\text { Test results } \mathbf{N}_{\mathbf{u} 1} \\
(\mathbf{k N})\end{array}$ & $\begin{array}{c}\text { Calculated results } \mathbf{N}_{\mathbf{u} 2} \\
(\mathbf{k N})\end{array}$ & $\begin{array}{c}\left(\mathbf{N}_{\mathbf{u} 1}-\mathbf{N}_{\mathbf{u}}\right) / \mathbf{N}_{\mathbf{u} 1} \\
(\mathbf{\%})\end{array}$ \\
\hline AC-1 & 527 & 522.2 & 0.91 \\
\hline AC-2 & 541.4 & 533.5 & 1.46 \\
\hline AC-3 & 530.6 & 534.0 & -0.64 \\
\hline AC-4 & 436.08 & 440.9 & -1.10 \\
\hline AC-5 & 397.4 & 342.1 & 13.92 \\
\hline AC-6 & 420.25 & 440.9 & -4.91 \\
\hline AC-7 & 482.82 & 440.9 & 8.68 \\
\hline AC-8 & 369.6 & 375.9 & -1.71 \\
\hline AC-9 & 374.1 & 339.1 & 9.36 \\
\hline AC-10 & 477.8 & 463.2 & 3.06 \\
\hline
\end{tabular}

The bearing capacity calculation model was used to estimate the proportion of the bearing capacity provided by each material, as shown in Fig. 12. The bamboo plywood had a high cross-sectional content ratio and provided a large proportion of the bearing capacity. By comparison, the thin-walled steel tube had a low cross-sectional content ratio but a high strength and hence contributed a large proportion of the bearing capacity. Although the stone dust concrete had a high cross-sectional content ratio, its proportion of the bearing capacity was small due to the low strength of the stone dust concrete material. The stone dust concrete played a role in determining the failure mode of the specimen under stress, improved the compression stability, and decreased deformation of the specimen. As revealed by comparison, the further optimization of the cross-sectional content ratio of stone dust concrete or an appropriate increase in the strength of stone dust concrete is expected to optimize the comprehensive performance of this new type of composite column in terms of its compressive bearing capacity and deformation capacity.

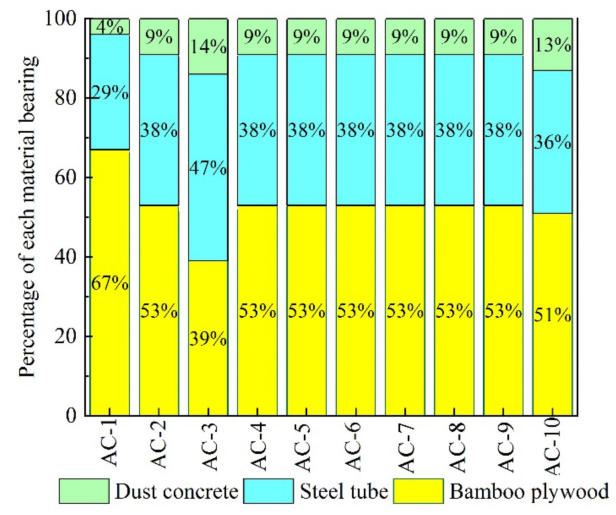

Fig. 12: Proportion of the bearing capacity. 


\section{CONCLUSIONS}

Experimental investigations of the performance of BSDCC specimens in compression were conducted in this study. The following conclusions were drawn from the results: (1) The axial compressive failure modes of the new type of BSDCC mainly included the adhesive cracking and debonding failure between the bamboo plywood boards and between the bamboo plywood and the steel tube and the compressive-flexural failure of the bamboo plywood between the binding bars in the middle of the specimen. The thin-walled steel tube in the bamboo plywood compressive-flexural failure zone buckled locally. (2) The ultimate bearing capacity of the BSDCC decreased as the specimen slenderness ratio and binding bar spacing ratio increased and increased with increasing stone dust concrete strength. The stronger the confinement of the bamboo plywood due to the cross-sectional composition and binding bar confinement pattern, the higher the ultimate bearing capacity. For the specimens considered in the present study, the cross-sectional content ratio of stone dust concrete had no significant effect on the ultimate bearing capacity of the BSDCC. (3) The encased low-intensity stone dust concrete could interact with the thin-walled steel tube and binding bars to improve the compressive stiffness and stability of the BSDCC specimens, thereby controlling the axial compressive failure mode and deformation capacity of the composite column. (4) The model for calculating the ultimate bearing capacity of such a composite column under axial compression is proposed on the basis of the test results and has an absolute error of less than $15 \%$. The calculation model can be used as a reference in future engineering applications.

\section{ACKNOWLEDGMENTS}

The authors acknowledge the financial support from the Science and Technology Planning Project of Guangzhou City (grant no. 201904010108) and the National Natural Science Foundation of China (grant no. 51708476).

\section{REFERENCES}

1. Arel, H.Ş., 2016: Recyclability of waste marble in concrete production. Journal of Cleaner Production 131:179-188.

2. Aliabdo, A.A., Abd Elmoaty, A.E.M., Auda, E.M., 2014: Re-use of waste marble dust in the production of cement and concrete. Construction and Building Materials 50: 28-41.

3. Febin, G.K., Abhirami, A., Vineetha, A., Manisha, V., Ramkrishnan, R., Sathyan, D., Mini, K., 2019: Strength and durability properties of quarry dust powder incorporated concrete blocks. Construction and Building Materials 228: 1-9.

4. GB/T228.1, 2010: Metallic materials-tensile testing: Method of test at room temperature.

5. GB 50005, 2017: Standard for design of timber structures.

6. GB/T 50081, 2019: Standard for test methods of concrete physical and mechanical properties.

7. He, M., Li, Z., Sun, Y., Ma, R., 2015: Experimental investigations on mechanical properties and column buckling behavior of structural bamboo. Structural Design of Tall and Special Buildings 24(7): 491-503.

8. Kumar, A., Vlach, T., Laiblova, L., Hrouda, M., Kasal, B., Tywoniak, J., Hajek, P., 2016: Engineered bamboo scrimber: Influence of density on the mechanical and water absorption properties. Construction and Building Materials 127: 815-827.

9. Kandolkar, S.S., Mandal, J.N., 2015: Behavior of reinforced stone dust walls under strip loading. Advances in Civil Engineering Materials 4(1):1-30. 
10. Li, H.T., Chen, G., Zhang, Q.S., Ashraf, M., Xu, B., Li, Y., 2016: Mechanical properties of laminated bamboo lumber column under radial eccentric compression. Construction and Building Materials 121: 644-652.

11. Li, H.T., Liu, R., Lorenzo, R., Wu, G., Wang, L.B., 2019: Eccentric compression properties of laminated bamboo columns with different slenderness ratios. Proceedings of the Institution of Civil Engineers-Structures and Buildings 172:315-326.

12. Li, H.T., Su, J.W., Zhang, Q.S., Deeks, A.J., Hui, D., 2015: Mechanical performance of laminated bamboo column under axial compression. Composites Part B: Engineering 79: 374-382.

13. Li, W.T., Long, Y.L., Huang, J., Lin, Y., 2017: Axial load behavior of structural bamboo filled with concrete and cement mortar. Construction and Building Materials 148: 273-287.

14. Liu, Y., Guo, Z.X., Xu, P.H., Jia, L., 2015: Experimental study on axial compression behavior of core steel reinforced concrete. Journal of Building Structures 36(4): 68-74.

15. Moroz, J.G., Lissel, S.L., Hagel, M.D., 2014: Performance of bamboo reinforced concrete masonry shear walls. Construction and Building Materials 61: 125-137.

16. Nayak,A.,2013: Replacement of steel by bamboo reinforcement. IOSR Journal of Mechanical and Civil Engineering 8(1): 50-61.

17. Reynolds, T., Sharma, B., Harries, K., Ramage, M., 2016: Dowelled structural connections in laminated bamboo and timber. Composites Part B: Engineering 90: 232-240.

18. Siddika, A., Mamun, M., Siddique, M., 2017: Evaluation of bamboo reinforcements in structural concrete member. Journal of Construction Engineering and Project Management 7(4): 13-19.

19. Singh, S., Nagar, R., Agrawal, V., 2016: A review on properties of sustainable concrete using granite dust as replacement for river sand. Journal of Cleaner Production 126(10): 74-87.

20. Sharma, B., Gatoo, A., Bock, M., Ramage, M., 2015: Engineered bamboo for structural applications. Construction and Building Materials 81: 66-73.

21. Tian, L.M., Kou, Y.F., Hao, J.P., 2019: Axial compressive behaviour of sprayed composite mortar-original bamboo composite columns. Construction and Building Materials 215: 726-736.

22. Wei, Y., Zhou, M.Q., Yuan. L.D., 2016: Mechanical performance of glulam bamboo columns under eccentric loading. Acta Materiae Compositae Sinica 33(2): 379-385.

23. Xiao,Y., Yang, R., Shan, B., et al., 2012: Experimental research on mechanical properties of glubam. Journal of Building Structures 33 (11):150-157.

24. Zhao, W.F., Gu, W., Zhou, J., Long, Z.L., 2016: Eccentric compression behavior of thin-walled steel-tube/bamboo-plywood assembling short hollow column with binding bars. Transactions of Chinese Society of Agricultural Engineering 15(32): 75-82.

25. Zhao, W.F., Yang, B., Zhou, J., 2019: Axial compressive creep behavior of a square steel tube/bamboo plywood composite column with binding bars. Wood Research, 64(2):2230-236.

26. Zhao, W.F., Luo, Z.J., Li, Y.J., 2020: Axial compression testing of bamboo-laminated encased steel tube composite columns. Iranian Journal of Science and Technology-Transactions of Civil Engineering 44(2): 645-655.

27. Zhang, Z.W., Li, Y.S., Liu, R., 2015: An analytical model of stresses in adhesive bonded interface between steel and bamboo plywood. International Journal of Solids and Structures 52: 103-113.

28. Zheng, D., Han, H., Hao, L., 2017: Influence of the amount of recycled dust on cement stabilized crushed stone base. Bulletin of the Chinese Ceramic Society 36(7): 2476-2480. 
Weifeng zhao

Guangdong Construction Polytechnic

Guangzhou

China

Weifeng Zhao, Zongjian Luo, Yajun Li

Xiangtan University

College Of Civil Engineering And Mechanics

Xiangtan

China

JiNG $Z_{\text {HOU }}{ }^{*}$

South China University Of Technology

Key Laboratory Of Subtropical Architecture Science

Guangzhou 5 IO640

China

"Corresponding author: ctjzhou@scut.edu.cn 